http://www.jfas.info

\title{
INVESTIGATING THE RELATIONSHIP BETWEEN KNOWLEDGE MANAGEMENT AND EMPLOYEES' EMPOWERMENT IN AGRICULTURE BANK OF TEHRAN
}

\author{
A. Ghorbani \\ Master of business management
}

Published online: 16 July 2016

\begin{abstract}
The purpose of current study is to investigate the relationship between knowledge management and employees' empowerment in Agriculture Bank of Tehran Province. Method is descriptive-survey and correlation type. Statistical population of the research is all employees of Agriculture Bank in Tehran that are 2800 employees. A sample of 338 respondents was selected based on Kochran's formula and simple random sampling approach. In this research, two questionnaires of knowledge management and employees' empowerment were used that their reliability has been confirmed by Cronbakh's alpha of 0.88 and 0.91 , respectively. Validity was also confirmed by experts' views. Data was analyzed by Spearman test and analysis of variance with SPSS software. It was shown that there is a significant relationship between knowledge management and the dimensions of employees' empowerment.
\end{abstract}

Keywords: Employees’ empowerment, Knowledge management, Agriculture Bank

Author Correspondence, e-mail: aeinghorbani84@gmail.com

doi: http://dx.doi.org/10.4314/jfasv8i2s.64 


\section{INTRODUCTION}

Recently, problem is not that how information should be acquired; but the problem is to how information is managed. Organizations managing their knowledge, would achieve a high level of productivity. Organizations can make better decisions, optimize the processes, reduce duplications, and increase innovations by accessing to the employees' knowledge. In recent era, organizations not only rely on having and managing knowledge for survival and growth, but also the society survival is dependent on the application of updated knowledge. To move toward a knowledge-oriented society, education is a main and critical pillar. As knowledge and information is the most important principle for productivity, economic competition, and development, human resources are the most important tool and capital of society for political and economic goal achievement; then, the governments put a higher priority for educating human resources. Education as an extended formal social institution should be pioneer in the establishment of knowledge management as a core competency compared to other organizations and plays a leadership role. Carol (2003) believed that knowledge management in education is a challenge that must be considered because available culture in education has been resided in a high individual level if not very unique[1]. Today's knowledge is a major component of organization success. This issue is important in cultural firms that intellectual capital and intangible assets are essential. If trend of knowledge change is not evaluated precisely, the result is that recent industrial society is an informational society that synergetic technologies would be replaced with knowledge-generator technologies. Organization survival is highly dependent on capabilities, skills, and various expertises of human resources. The more readiness of employees, the higher level of organizational efficiency . As all organizations are affected by technology advancement, they should adapt their self with the advancement in multiple aspects to survive. The infrastructure of the changes is empowerment and utilization of human resources [2]. An organization needs to develop their human resources and the existing knowledge and information to be excellent compared to other organizations. Knowledge management, generation, acquisition, collection, and 
distribution of knowledge are to increase learning and improve performance as well as empower employees. Employees and their implicit knowledge are valuable resources for the organizations. Knowledge and how-to-know are strategic resources of organization that should be managed and developed. Hence, organizational learning and knowledge generation attracted more attention in recent years [3].

Empowerment is a new and influential technique to enhance organizational productivity using employees' abilities. Employees have power because of their knowledge, experience and motivations. In fact, empowerment leads to giving up the power. Application of potential capabilities is a competitive advantage for any organization. Research indicated that capable individuals are great capitals for organization and management as they are leader and reliable and have the capability of adapting with internal and external changes of organization. This has more importance in educational institutions such as education system and its managers because education system is a comprehensive and dynamic institution that affects on behaviors and implicit and explicit ethical, political, economic, religious, law, social and cultural norms of society. The nature of activities and their goals are to enhance creativity, to foster talent, to improve public and specialized awareness, and to determine the strategies for growth and development. Research conducted in Iran showed that education system management of Iran has not a suitable framework for employees' empowerment [4].

Further, empowerment is a process that manager helps to employees in an attempt to achievement of independent decision-making capability. This process not only affects employees' performance but also their personality. The most important concept of empowerment is authority distribution among lower levels of organization. Decision making process should have a high level of decentralization and individuals or groups should be responsible for a complete part of work processes [5].Empowerment is, in fact, a type of pioneer technology that provides organizations with strategic advantage and creates entrepreneurship opportunities. Hence, a manager task in empowerment program is not to give power, but he/she should provides them with opportunities for utilization of the capabilities and potentials of employees. The advantages of empowerment are:

1. Ownership feelings of employees towards work process would increase. 
2. It leads to creativity of employees that have some benefits for organization.

3. Empowerment activities lead to compensation such as informational rights, welfare, rewards, and so on.

4. Empowerment approaches lead to favorable social goal achievement .

In order to managers can empower employees, certain characteristics need to be available (empowerment dimensions):

- Self-capability (self-effectiveness): when people are empowered, they feel self-efficiency or they feel that have required capability and skill for successful performance [6].

- Having selection right (self-organization): it means that employees have freedom and independence for determining necessary activities to conduct job tasks.

- Feeling of being effective (acceptance of personal results): this dimensions refers to the extent in which behavior of employee is seen in doing various job goals; that is, expected results have been achieved in job environment [7].

- Feeling of being significant or important (valuable): it includes the consistency between job requirements and believes or values. Significant is the fit between work requirements, believes, values and behaviors [8].

- Feeling of having trust (self-esteem): trust refers to have personal security feeling [9].

When managers can foster the characteristics in employees, they have been successfully empowered. Empowered personnel can not only do their tasks, but also they think differently about their-self [10]. Before defining knowledge management, it is necessary to know what means knowledge. Oxford dictionary has defined knowledge as all implicit information of people that can be achieved by the experience. Further, knowledge has been defined as organized information [11].NASA has defined knowledge management as the achievement of right information in time and from right people and help to employees in an attempt to creation and share of knowledge using information in a way that NASA performance and its partners would be improved [12].Hains considered knowledge management as process with four principles: 
1. Content: it is related to knowledge type (implicit or explicit)

2. Skill: it is associated with abilities achievement to extract knowledge

3. Organization: it is related to organizing available knowledge

4. Culture: organization culture should encourage distribution of knowledge and information [13].

Knowledge management is considered as the brain of organization and equips employees to knowledge and information to do their task correctly and making right and quick decisions. Knowledge is the most important soft asset of organizations. Correct management of the assets is a key factor in superiority and competitiveness of organizations in recent era. To develop knowledge, it should be communicated with organizations, institutions and knowledge pools outside of the firm. It should be noted that a part of required knowledge are with us and another part is with them. Hence, leadership of a knowledge based organization should continuously communicate with scientific forums and academics as a strategic goal as well as find effective solutions for communicating with current and potential customers [14].To implement knowledge management in training institutions, six issues should be considered: awareness establishment by technology, development of attitudes to be innovative, usage of training tests by technology, application of technology to determine the boundaries of how-to-know, analysis of human capital establishment, and usage of knowledge management to maximize effective learning [15].

In general, knowledge management process includes following activities:

1. Knowledge identification: it is an effort to determine gaps and shortages of knowledge in an organization. The greater gap, the harder strategic goal achievement. In this case, many organizations have internally and externally established a plan of knowledge, data, information and required skills [16].

2. Knowledge acquisition: after identification of knowledge, knowledge should be acquired. In other words, in this stage, knowledge needs to be acquired from the internal and external market such as knowledge regarding customer, production, colleagues, rivals, and so on. 
3. Knowledge development: development of knowledge management includes all management efforts to establish capacities that have not been established yet. In this regards, usage of specialized groups, groupware tools, assignment of places to form groups, internet, video conference, reviewing activities after doing them and multipurpose training of employees are effective actions.

4. Distribution of knowledge: one of the main parts of knowledge management is knowledge transfer in which an organization distributes information among its members and learning is improved through the task to create a new understanding.

5. Knowledge application: the final goal of knowledge management is to use for organizational performance improvement. Many experts know this stage as an important stage in knowledge management process because competitive advantage is not lonely relied on having rich and frequent knowledge but it is relied on the application of knowledge resources in organizational operations and decisions. When employees have used the best practices in new situations to improve their performance, they modify the practices and a new set of practices is generated .

The results of prior research indicated that knowledge management acquisition and scientific information management play a critical role in managers' empowerment. Spritzer (2014) investigated employees' empowerment with job performance and showed that self-esteem, availability of information about the organization, job performance, innovative behaviors in employees have a positive relationship with empowerment. Kanter (2013) concludes that each dimension of empowerment is associated with behaviors that improve performance. People who feel more significance or attention towards them, they would have more efforts for their works and are more committed to their tasks. Rabintz et al. (2010) revealed that to foster empowerment, to acquire needed knowledge, to provide required information, to encourage self-management, and to encourage goal-setting, training of employees is important. Golini (2012) identified factors influencing managers and teachers' empowerment including attention to the role of human resources, awareness of management skills, attention to a certain management style, employees' training, fostering managers and teachers in a way that they try to develop their professional skills, and implying on the implementation of 
knowledge management in schools. Solgi (2010) in his study on knowledge management in schools showed that knowledge management enhances managers' skills and as a result, knowledgeable humans would be educated in the schools. Hasani (2008) studied the relationship between knowledge management and human resource development and showed that experience transfer, creativity, participation and modeling are the main priorities of knowledge management in the process of empowerment. In this research, the relationship between knowledge management and empowerment of agriculture Bank of Tehran Province would be examined. According to the important aspects of employees' empowerment, the measurement of its dimensions, including self-esteem, self-effectiveness, feeling of effectiveness, and feeling of being significance, play key role in organization. Then, the availability of relationship between knowledge management in organization and employees' empowerment would be examined. Finally, the research tries to answer the question that "is there any significant relationship between knowledge management and employees' empowerment of Agriculture Bank of Tehran Province?". The main and sub hypotheses are as following:

Main hypothesis: There is a significant relationship between knowledge management and employees' empowerment in Agriculture Bank of Tehran Province.

\section{Sub-hypotheses:}

1. There is a significant relationship between knowledge management and feeling of being significance among employees of Agriculture Bank in Tehran Province.

2. There is a significant relationship between knowledge management and employees' self-esteem of Agriculture Bank in Tehran Province.

3. There is a significant relationship between knowledge management and feeling of being effective among employees of Agriculture Bank in Tehran Province.

4. There is a significant relationship between knowledge management and self-effectiveness of employees of Agriculture Bank in Tehran Province.

5. There is a significant relationship between knowledge management and self-organization of employees of Agriculture Bank in Tehran Province. 


\section{Methodology}

The research method is descriptive-survey one. It is descriptive because of providing a snapshot of current situation and it describes current status in a regular and systematic. It is also survey research because of gathering data from sampling method to investigate statistical characteristics of population [17].Further, as the relationship between dependant and independent variables is examined, it is a correlation research. The research is applicable in terms of objective. Social sciences research use statistical population and enough samples to consume lower resources, time and facilities. Then, the results of sample are generalized to the population [18].statistical population is all employees of Agriculture Bank of Tehran Province who are 2800 people. Based on Kochran's formula, sample size estimated at 338 employees. Sampling approach was simple random sampling. The instrument was a self-administrated questionnaire. Required data was gathered by questionnaire to test hypotheses. In this research, to measure employees' empowerment, standardized questionnaire of Vatan and Kameron was used. This questionnaire includes 21 questions with Likert scale. To measure knowledge management level, a self-administrated questionnaire was used containing 19 items. As the standard questionnaire of empowerment was used and self-administrated questionnaire of knowledge management was confirmed by the experts, then, the validity of instrument is approved. The reliability of questionnaire was confirmed by Cronbach's alpha of 0.88 and 0.91 , respectively for empowerment and knowledge management. To investigate the correlation between research variables, Spearman test was employed. In this stage, researcher uses statistics by sample data. Then, using estimation and testing statistical hypothesis, statistics are generalized to the society. Correlation test would examine the relationship between two or more variables. Correlation may be positive or negative [19]. 


\section{Findings}

Testing main hypothesis: There is a significant relationship between knowledge management and employees' empowerment in Agriculture Bank of Tehran Province.

Table 1 shows research and statistical hypotheses as well as the results of test.

As significant level of statistic is below $0.05, \mathrm{H} 0$ is rejected and there is correlation between the two variables. Correlation coefficient is 0.784 for 338 data.

Table 1. The results of Spearman correlation between knowledge management and employees' empowerment

\begin{tabular}{|c|c|c|c|c|c|}
\hline \multicolumn{5}{|c|}{$\begin{array}{l}\text { Is there any significant relationship between knowledge management and } \\
\text { employees' empowerment in Agriculture Bank of Tehran Province? }\end{array}$} & Question \\
\hline \multicolumn{4}{|c|}{$\begin{array}{l}\text { There is not a significant relationship between knowledge management } \\
\text { and employees' empowerment in Agriculture Bank of Tehran } \\
\text { Province. }\end{array}$} & HO & \multirow{2}{*}{$\begin{array}{l}\text { Research } \\
\text { hypothesis }\end{array}$} \\
\hline \multicolumn{4}{|c|}{$\begin{array}{l}\text { There is a significant relationship between knowledge management and } \\
\text { employees' empowerment in Agriculture Bank of Tehran Province. }\end{array}$} & $\mathrm{H} 1$ & \\
\hline \multicolumn{4}{|c|}{$\mathrm{H}_{0}: \rho=0$} & H0 & \multirow{2}{*}{$\begin{array}{l}\text { Statistical } \\
\text { hypothesis }\end{array}$} \\
\hline \multicolumn{4}{|c|}{$\mathrm{H}_{1}: \rho \nexists$} & $\mathrm{H} 1$ & \\
\hline Result & $\begin{array}{l}\text { Significance } \\
\text { level }\end{array}$ & $\begin{array}{l}\text { Standard } \\
\text { error }\end{array}$ & \multicolumn{2}{|c|}{ Spearman test } & \multirow{2}{*}{ 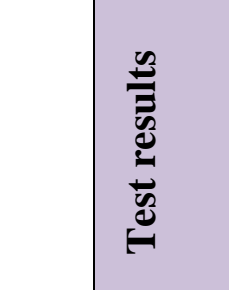 } \\
\hline $\begin{array}{l}\text { H0 was } \\
\text { rejected }\end{array}$ & 0.000 & 0.05 & \multicolumn{2}{|l|}{0.784} & \\
\hline
\end{tabular}

The results of sub-hypotheses testing have been illustrated in Table 2. 
Table 2. Spearman coefficients of sup-hypotheses

\begin{tabular}{|c|c|c|c|c|}
\hline Result & $\begin{array}{c}\text { Significant } \\
\text { level }\end{array}$ & $\begin{array}{c}\text { Standard } \\
\text { error }\end{array}$ & Spearman test & Hypothesis \\
\hline Supported & 0.000 & 0.05 & 0.675 & H1-1 \\
\hline Supported & 0.000 & 0.05 & 0.743 & H1-2 \\
\hline Supported & 0.000 & 0.05 & 0.728 & H1-3 \\
\hline Supported & 0.000 & 0.05 & 0.654 & H1-4 \\
\hline Supported & 0.000 & 0.05 & 0.711 & H1-5 \\
\hline
\end{tabular}

The results indicated that significance level is below 0.05. All hypotheses were supported. It means that there is significant relationship between empowerment dimensions (self-organization, self-esteem, self-effectiveness, feeling of effectiveness, and feeling of being significance) and knowledge management among employees of Agriculture Bank of Tehran Province. Thus, with confidence level of 95 percents, the research hypotheses were supported. Further, regression analysis was used to investigate the linear relationship between the two variables: 
Table 3. The results of regression analysis between knowledge management and employees' empowerment

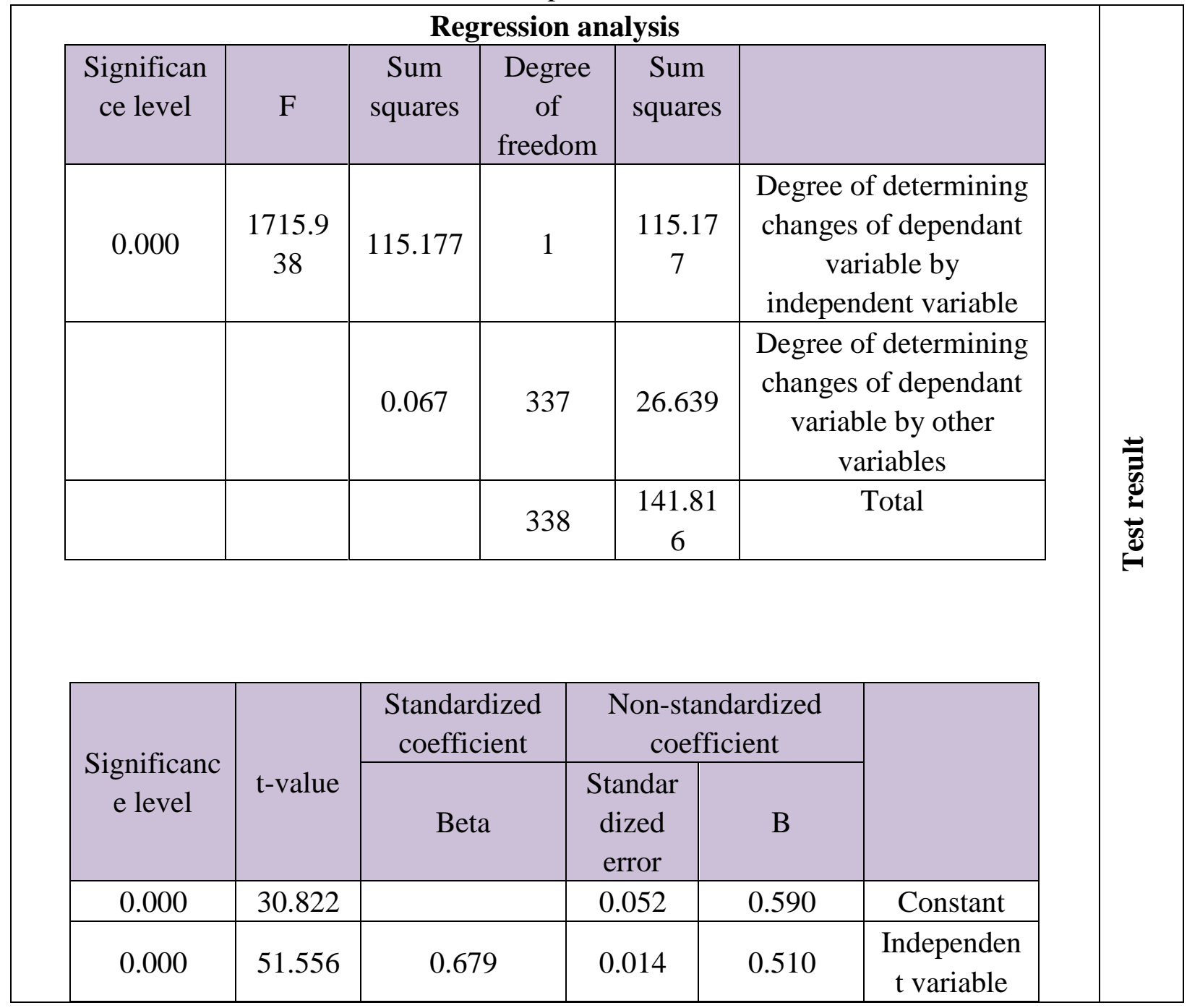

According to the significance level that is below 0.05 , linearity of relationship between the two variables is supported. Thus, in this hypothesis, regression equation is (employees' empowerment $=0.679$ knowledge management $)$. The results of regression analysis for other hypotheses have been proposed in table 4 . Hence, the linear relationship between the two variables is supported. 
Table 4. The result of regression analysis of hypotheses

\begin{tabular}{|c|c|c|}
\hline Result & Regression equation and Beta & Hypotheses \\
\hline Supported & $\begin{array}{c}\text { Feeling of being significance= } 0.571 \text { knowledge } \\
\text { management }\end{array}$ & H1-1 \\
\hline Supported & Self-esteem=0.631 knowledge management & H1-2 \\
\hline Supported & Feeling of being effective=0.676 knowledge \\
management & H1-3 \\
\hline Supported & Self-effectiveness=0.545 knowledge management & H1-4 \\
\hline Supported & Self-organization=0.507 knowledge management & H1-5 \\
\hline
\end{tabular}

\section{CONCLUSION}

Organizations need not only to creativity and innovation, but also to knowledge acquisition. A supportive climate, originated from knowledge management in a suitable way, can apply knowledge and organizational learning to solve problems in anytime and anyplace. Knowledge management uses a set of important processes and strategic knowledge management to improve the identification of limitations, opportunities and challenges. It would not be possible unless with the establishment of a participative climate, encouragement to be innovative, and motivating employees to produce knowledge. The results showed that there is significant relationship between dimensions of employees' empowerment (self-organization, self-esteem, self-effectiveness, feeling of effectiveness, and feeling of being significance) and knowledge management. It means that the better situation of knowledge management among employees of Agriculture Bank of Tehran, the more employees' empowerment. In other words, knowledge management is an antecedent of successful employees' empowerment. To achieve this goal, employees should perform their tasks appropriately and have necessary knowledge and abilities as well as be aware of organization goal. A tool can help managers is knowledge management process and employees' empowerment. Finally, the following implications are presented: 
1. Mangers should utilize the abilities and creativity of employees in implementing knowledge management system. This would lead to more empowered employees. Further, managers should appreciate teamwork that is in line with common goal of organization and address to development of employees' skills and capabilities. Managers can invest to improve employees' abilities and cooperation in organizational activities in an attempt to enhance the level of participation among organization members.

2. It is suggested that bank managers use high capacity and experience of employees in implementing knowledge management system. In addition, they should improve their understanding from customer needs to enhance organization adaptability.

3. It is suggested that managers should use the strengths of employees (awareness degree to conduct successful performance and consistency of short-term solutions with long-term vision) to implement knowledge management system.

4. It is suggested that managers use high coordination of organizational departments in projects. Further, certain values for doing organizational affairs and mutual agreement can be considered as strengths to implement knowledge management system.

Managers should create shared vision in various departments through which can encourage organizational capabilities.

\section{REFERENCES}

[1] Carol, K. Knowledge management in the view of a trade strategy, Translated by Sedigheh ahmadi Fasih, Quarterly Information Science, 2003, 18(3).

[2] Taghipor, A. and Jahanian, R, Investigating the dimensions of empowerment of training managers to propose a framework for school managers of country, Journal of Managament Research, 2008, 83: 87-102.

[3]. Hornstein, H,(2006), Empowerment as a way to facilitate change .

[4]. Education Ministry (2002), Document of Education System Modification, Education Research Institute, first edition. 
[5]. Lawler, E, (2010), Total quality management \& employee involvement: are they compatible, Academy of Management Executive.

[6]. Hasanpor, A and Moghli, A. Investigating the relationship between empowerment and organizational commitment of employees in 19 regions of Education Organization of Tehran Province, Public Administration Journal, 2008, 1(2): 61-78.

[7]. Thomas, K. and Betty, A. cognitive elements of empowerment: An interpretation model of intrinsic task motivation, Academy of Management Journal, 2011, 10(4): 661-681.

[8]. Spritzer, G, Psychological empowerment in the workplace: Dimensions, Measurement and Validation," The Academy of Management Journal 2014, 738: 1442-1465.

[9]. Kordnaeej, A, The relationship between empowerment and organizational learning, Research Journal of Change Management, 2009, 2(3): 112-125.

[10]. Vatan, D. and Kameron, K. (2001), Empowerment and authority, Translated by Oraei Yazdi, Institute for research and training of management, Tehran.

[11]. Oxford, Advanced learners Dictionary of current English,(2000), 6thed.

[12]. Gaffari, M, Fesharaki, M, and Akhayan, A.(2007). Establishing an integrated K M system in Iran Aerospace Industries organization, Journal of knowledge management, vol.11 No.1, pp127-142.

[13]. Abtahi, H. and Salavati, A. (2005), Knowledge management in organization, Tehran: Peivande Noe Publication.

[14]. Soori, H. and Beikzadeh Marzbani, N. (2005), Organizational leadership and human resource empowerment in knowledge management model, Forth international conference of management, Tehran.

[15]. Mary, R. (2005). the contribution of Knowledge management to learning: practice and potential and Newzealand School.

[16]. Sarlak, M. (2006), Knowledge management, First edition, Payame Noor Publications.

[17]. Hafeznia, M. R. (2005), Introduction to methodology of social sciences, SAMT Publications.

[18]. Bazargan, A. (2005), Research methods in Social Sciences, Agah Publications. [19]. Azar, A. (2009), Statistics and its application in management, SAMT Publications. 


\section{How to cite this article:}

Ghorbani A. Investigating the relationship between knowledge management and employees' empowerment in agriculture bank of Tehran. J. Fundam. Appl. Sci., 2016, 8(2S), 1429-1443. 